DOI: $10.20472 / \mathrm{IAC} .2017 .33 .064$

RAJEEV SHARMA

Charles Darwin University, Australia

\title{
EXPLORING THE SOCIAL MEDIA BELIEFS OF INDIVIDUAL AND INSTITUTIONAL USERS IN AUSTRALIA
}

\begin{abstract}
:
Social media is now a communications tool of choice for many individuals, commercial and not for profit organizations. There is compelling evidence that mainstream Australians are avid social media users. Understanding of social media consumption and its impact is important for a wide range of stakeholders. The objective of this study is to better understand the beliefs that drive social media consumption in the Northern Territory Australia. Primary data for this paper was obtained through an on-line survey. Based on 420 usable responses, this paper explores the underlying beliefs of individual and institutional social media users. Data analysis identified statistically significant differences in the beliefs of the two cohorts.
\end{abstract}

\section{Keywords:}

social media, beliefs, Australia

JEL Classification: M19 